\title{
El sustrato cientificista de la antropología estructural: una crítica desde la hermenéutica (primera parte): Las raíces positivistas y cartesianas de la antropología estructural
}

\author{
The Scientificist Substrate of Structural Anthropology: \\ A Hermeneutic Criticism (First part): \\ Positivist and Cartesian Roots \\ of Structural Anthropology
}

\author{
Julio Amador Bech \\ Facultad de Ciencias Políticas y Sociales \\ Universidad Nacional Autónoma de México
}

\begin{abstract}
RESUMEN: El presente artículo se propone elaborar una crítica sistemática de los presupuestos teóricos que subyacen a la antropología estructural de Claude Lévi-Strauss. Para tal fin se parte de una reconstrucción hermenéutica de sus principales planteamientos, dados en su obra Antropología estructural, en particular, su proposición de tomar a la lingüística estructural y, dentro de ésta, a la fonología de Trubetzkoy, como modelo de cientificidad para la antropología. Se trata de mostrar que a pesar de que su modelo parece provenir de las ciencias sociales, en realidad, el concepto de cientificidad que rige el estructuralismo de Lévi-Strauss no es el de la lingüística, sino el de las ciencias naturales, y, en ese sentido, su pensamiento es afín al positivismo y al cartesianismo. Esos principios son los que, en términos teóricos, rigen el extenso estudio de los mitos que desarrolla en Mitológicas. En consecuencia, propongo que la perspectiva hermenéutica desde la cual se deba abordar el estudio del mito, en particular, y de la problemática de la etnografía, en general, no es el del estructuralismo de Lévi-Strauss, sino que el proceso de comprensión debe realizarse de modo que no se violente la especificidad cultural propia de los grupos humanos que se estudian, y el ser humano vivo vuelva a estar en el centro de la antropología.
\end{abstract}

ABSTRACT: The present article intends to accomplish a systematic critique of the theoretical basis that underlie Claude Lévi-Strauss' structural anthropology. With that in mind, we begin with an hermeneutic reconstruction of its main propositions, starting from the basic ideas presented in his work Structural Anthropology, in particular, his suggestion concerning the idea of using structural linguistics, and especially Trubetzkoy's phonology, as a scientific model for anthropology. I try to demonstrate that, even though that model seems to come from social sciences, actually, the concept of scientific rigor that rules LéviStrauss's structuralism comes from the natural sciences, and, in that sense, his thought is akin to positivism and cartesianism. Those are the theoretical principles that guide the full and detailed study of myth that is elaborated in Mythologiques. In consequence, I propose that the hermeneutic perspective from which, in particular, the study of myth should be dealt with and, in general, the question of ethnography, is not that of Lévi-Strauss's structuralism. The process of comprehension should occur in another way, so that the specific cultural traits of the human groups that are studied and the living human being will return to the center of anthropological thought. 
PALABRAS ClAVE: cientificismo, antropología estructural, hermenéutica, interpretación del mito.

KEYWORDS: scientism, structural anthropology, hermeneutics, myth interpretation.

RECIBIDO: 13/04/2016 • ACEPTADO: 15/11/2016 
Julio Amador Bech

Facultad de Ciencias Politicas y Sociales

Universidad Nacional Autónoma de México

\section{El sustrato cientificista de la antropología estructural: una crítica desde la hermenéutica (primera parte): Las raíces positivistas y cartesianas de la antropología estructural}

Lo cómico o, más correctamente, lo trágico de la situación actual de la ciencia es, en primer lugar, el pensar que se puede superar el positivismo mediante el positivismo.

Martin HeIDEgGer

La desvalorización más evidente de los símbolos que nos presenta la historia de nuestra civilización es, sin duda, la que se manifiesta en la corriente científica surgida del cartesianismo.

GiLbert DuRAND

Paul Ricoeur define al texto como "todo discurso fijado por la escritura. Según esta definición, dicha fijación es constitutiva del propio texto" (Ricoeur 1999: 59). Particularmente en el caso de los problemas que plantea el descifrar un texto, Ricoeur se propondrá resolver la aparente contradicción que existía en la hermenéutica de Dilthey entre los conceptos de explicación, proveniente de las ciencias naturales, que los 
positivistas hicieron extensivas a las ciencias históricas, y el de interpretación, entendida como una forma de la comprensión, proveniente de las ciencias del espíritu (Ricoeur 1999: 59). Afirmará que, a partir del estructuralismo de Lévi-Strauss, "la noción de 'explicación', en efecto, ha sido desplazada: ya no es un término heredado de las ciencias de la naturaleza, sino de modelos propiamente linguísticos" (Ricoeur 1999: 59). A partir de tal conclusión se dedicará a mostrar la complementariedad entre la explicación y la comprensión en los procesos de lectura e interpretación.

En cuanto a esta última cuestión, presento un punto de vista distinto al de Ricoeur, pues trataré de mostrar dos cosas: primero, que, en el trasfondo del estructuralismo de Claude Lévi-Strauss, el concepto de cientificidad que rige su pensamiento no es el de los modelos lingüísticos, sino el de las ciencias naturales y que, en ese sentido, su pensamiento es afín al positivismo y al cartesianismo; y segundo que, en consecuencia, la perspectiva hermenéutica desde la cual se debe abordar el estudio del mito, en particular, y de la problemática de la etnografía, en general, no es la de Lévi-Strauss, sino que el proceso de comprensión debe realizarse de otra manera, de modo que no se violente la lógica cultural, propia de la tradición cultural investigada. Sin embargo, en lo que se refiere a la crítica que lleva a cabo Ricoeur de otros aspectos de la antropología estructural, que presento más adelante, estoy plenamente de acuerdo con él.

Comienzo mi texto con la reconstrucción de los aspectos que considero nodales de la obra de un autor que estuvo en el centro de las polémicas sobre la teoría antropológica hace ya por lo menos 50 años y que hoy, aunque olvidado por algunos y recordado recientemente, en el centenario de su nacimiento (2008), por autores de las más diversas tendencias, sigue vigente dentro del ámbito académico mexicano, tanto en el de la antropología como en el del análisis estructural de textos. Por tal motivo, considero pertinente abordar la crítica de su teoría antropológica y su método analítico. Desde un punto de vista hermenéutico, volver a él resulta fundamental para retrazar el camino recorrido por las ideas cientificistas en la antropología, en particular, y en las humanidades y las ciencias sociales en un sentido más amplio.

En 1945 Claude Lévi-Strauss escribía: 
En el conjunto de las ciencias sociales, del cual indiscutiblemente forma parte, la lingüística ocupa sin embargo un lugar excepcional: no es una ciencia social como las otras, sino que, con mucho, ha realizado los mayores progresos; sin duda la única que puede reivindicar el nombre de ciencia y que, al mismo tiempo, ha logrado formular un método positivo y conocer la naturaleza de los hechos sometidos a su análisis (LéviStrauss 1970: 29).

Más tarde el referido artículo sería publicado en su Antropología estructural. En él se partía de un presupuesto básico que se sustentaba, de manera directa, en los desarrollos de la lingüística estructural, la cual había salido a la luz a partir de la publicación del Curso de lingüística general de Ferdinad de Saussure en 1916, cuyo texto contenía los apuntes tomados por sus discípulos Charles Bally y Albert Sechehaye durante los cursos impartidos por él entre 1906 y 1911 y parte de sus notas personales. Paul Ricoeur resume de manera muy precisa en qué consistió dicha aportación y cuáles fueron algunas de sus consecuencias. Así, explica que la necesidad de construir un objeto de estudio científico, riguroso y bien delimitado llevó a las ciencias del lenguaje, y en particular a la lingüística estructural, a "poner entre paréntesis la relación del lenguaje con la realidad" (Ricoeur 1999: 42).

La distinción, establecida por Saussure, entre lengua y habla formaba parte de la misma intención de cientificidad. De tal suerte que, a partir del mencionado Curso de lingüística general, entendemos la lengua como el conjunto sistemático de un idioma en el plano de la pura formalidad estructural, en su estatuto de conjunto de signos y reglas combinatorias pertenecientes a un código de comunicación socialmente aceptado como las convenciones sociales necesarias para la comunicación verbal y escrita. La lengua corresponde al conjunto de los signos que sirven como medio de comprensión entre los miembros de una misma comunidad lingüística y al conjunto de entidades entre las que se elige en las libres combinaciones del discurso. En el Curso el autor entiende a la lengua como "una determinada parte del lenguaje [...] un producto social de la facultad del lenguaje y un conjunto de convenciones necesarias adoptadas por el cuerpo social para permitir el ejercicio de esa facultad en los individuos" (Saussure 1979: 51). Asimismo, define la 
lengua como "un sistema de signos que expresan ideas" y, más aun, lo considera "el más importante de todos esos sistemas" (1979:60).

Por habla se designan los usos diversos y coloquiales que los individuos de esa comunidad hacen de la lengua por medio de una ejecución psicofisiológica, la actuación individual y las libres combinaciones del discurso (Saussure 1979: 49-66; Leroy 1992; Ricoeur 1999). El habla es esencialmente un acto individual de selección, uso y renovación; está constituida, ante todo, por las combinaciones gracias a las cuales el usuario puede utilizar el código del lenguaje para expresar su pensamiento personal (Barthes 1993). Mediante ese proceder, propio del enfoque epistemológico de la comunicación, "se logra aislar un objeto homogéneo: la lengua" (Ricoeur 1999: 42). De tal suerte, Saussure afirmará que "es la lengua lo que hace la unidad del lenguaje" (1979: 53). Y, tal como lo destaca Ricoeur, sostiene la idea de que mientras el lenguaje es un fenómeno heterogéneo, la lengua es homogénea, es un sistema de signos (Saussure 1979: 58).

La distinción entre lengua y habla se complementa con cuatro postulados que terminan por definir objeto y método, tanto de la lingüística estructural, como de las ciencias del lenguaje que de ella se derivan: 1) En la lengua se distinguen una ciencia sincrónica que estudia los estados del sistema, y una ciencia diacrónica que estudia los cambios del mismo; 2) se subordina la segunda a la primera; 3) en un estado del sistema no existen estados absolutos, sino únicamente relaciones de dependencia mutua; 4) con el objeto de analizarlo, el conjunto de los signos ha de ser considerado como un sistema cerrado (Ricoeur 1999: 42-43). En el Curso podemos leer la manera en la cual se llega a tal conclusión:

Al dar a la ciencia de la lengua su verdadero lugar en el estudio del lenguaje, hemos situado al mismo tiempo la lingüística entera. Todos los demás elementos del lenguaje, que son los que constituyen el habla, vienen por sí mismos a subordinarse a esta ciencia primera, y gracias a tal subordinación todas las partes de la lingüística se encuentran en su lugar natural (Saussure 1979: 63).

Así, mientras que el habla es el uso infinito de un sistema finito (la lengua), la lingüística estructural opta por el estudio de la lengua, de tal 
suerte, el sistema a analizar no tendrá partes externas, sino meras relaciones internas (Ricoeur 1999: 43). Tal como lo aclara Gilbert Durand:

El objeto de la linguística se vuelve a cerrar claramente entonces en el sistema lingüístico, en la célebre afirmación que pone fin al Curso: "La lingüística tiene por único y verdadero objeto la lengua considerada en sí misma y para sí misma" [...] Es el sistema cerrado y autosuficiente "en sí mismo y para sí mismo" el que confiere su valor semántico al signo, es decir al conjunto indisoluble significante-significado [...] Otra paradoja más grave se observó en la noción axiomática de sistema: un solo cambio, un solo aumento o disminución de signo cambia todo el sistema [...] de ahí la reticencia saussuriana a abordar los problemas de la transformación de los sistemas, de la "diacronía" [...] "el cierre" del sistema relativiza al mismo tiempo cada una de sus partes respecto de las demás, y lo hace monolítico e intangible (Durand 1993:52-53).

Justamente, el Curso concluye con la afirmación que cita Durand:

De las incursiones que acabamos de hacer por los dominios limítrofes de nuestra ciencia, se desprende una enseñanza enteramente negativa, pero también más interesante cuanto concuerda con la idea fundamental de este curso: la lingüística tiene por único y verdadero objeto la lengua considerada en sí misma y por sí misma (Saussure 1979:364).

Además, para el efecto de un supuesto rigor científico, la lingüística estructural deberá eliminar un aspecto fundamental de la definición de signo que entre los estoicos aparecía como significante, significado y cosa referida, mientras que en san Agustín y en la escolástica aparecía como la relación entre signum y res. Al excluir la referencia a lo real extralingüístico, se elimina de la comunicación al ser humano vivo y a la intersubjetividad. "En la lengua, nadie habla", concluye Ricoeur (1999: 44). Expulsados de la lingüística estructural - y de la llamada semiología, que de ella se derivó-, el habla, el hablante, su interlocutor y el mundo que sus discursos refieren, deberán ser estudiados por otras disciplinas como la hermenéutica, la pragmática, la antropología lingüística, la sociolingüística y la psicología de la comunicación, cuyo asunto a estudiar son los procesos vivos de la comunicación. Esta breve 
síntesis de los enunciados principales del Curso resulta fundamental en la medida en la cual el propio Lévi-Strauss hará referencia directa a los mismos para formular su método estructural de análisis del mito, tal como lo veremos en la segunda parte de este artículo, independientemente de que en otras cuestiones puedan existir diferencias teóricas entre ambos.

Hacia finales de los años ochenta, Giorgio Raimondo Cardona criticó el concepto, dominante hasta ese momento, de lengua:

En la lingüística moderna se ha aceptado ya una clase de concepción corriente de la lengua entendida como sistema de signos en el que tout se tient. Semejante concepción revela sus limitaciones ya en un nivel de puro análisis lingüístico, puesto que la simple observación de la variabilidad que caracteriza cualquier hecho lingüístico pone en crisis el concepto de sistema, por lo menos en su acepción corriente. Pero menos válida se manifiesta esta noción cuando tratamos de imaginar - sobre la base de hechos empíricos reales y no sobre la base de la lengua inexistente de una cultura inexistente - las conexiones entre operaciones y representaciones mentales, entre formas lingüísticas y elementos culturales no lingüísticos (Cardona 1994: 115).

Ricoeur intentará corregir, a pesar de la sociología de la comunicación, derivada de la lingüística estructural y en particular de la de Jakobson, estas deficiencias evidentes en el Curso; y que tratará al lenguaje “directamente en su función social", éste será concebido instrumentalmente "como un objeto de intercambio" (1999: 45). La parte sustantiva del problema deriva de la dependencia teórica del modelo jakobsoniano respecto de las teorías informáticas de la comunicación (Amador 2011; Hymes 1974; Kerbrat-Orecchioni 1997; Ricoeur 1999; Winkin 1984). Las teorías y modelos de la comunicación basados en un paradigma informático e instrumental, presentan también importantes limitaciones para comprender la complejidad del proceso vivo que la comunicación humana plantea. Desde esta perspectiva podremos ver que el problema fundamental de los modelos estructurales de la comunicación es que parten de un punto de vista epistemológico, es decir, entienden el asunto como un problema de método y pretenden ver a la comunicación desde fuera, como un objeto externo al ser humano, sometido al análisis de 
una "ciencia objetiva". En esto consiste su más grave debilidad teórica. Hans-Georg Gadamer ha mostrado que "en las ciencias del espíritu no puede hablarse de un 'objeto idéntico' de la investigación, del mismo modo que en las ciencias de la naturaleza" (1999: 353).

Volviendo a la teoría antropológica de Léví-Strauss, destaco que éste acude especialmente a las aportaciones de la fonología, en particular, a la obra de Trubetzkoy, afirmando que: "La fonología no puede dejar de cumplir, respecto de las ciencias sociales, el mismo papel que la física nuclear, por ejemplo, ha desempeñado para el conjunto de las ciencias exactas" (Lévi-Strauss 1970:31). Agrega que la fonología "busca descubrir 'leyes generales' ya sea que las encuentre por inducción o bien 'deduciéndolas lógicamente, lo cual les otorga un carácter absoluto"” (1970: 31). Y concluye que: "De esta manera y por primera vez, una ciencia social logra formular relaciones necesarias" (1970:31).

En la argumentación de Lévi-Strauss destaca el concepto de sistema como conjunto estructurado de relaciones necesarias entre las partes que lo componen, concepto que trasladará al estudio etnográfico, con el fin de sistematizar, desde su punto de vista, de una manera rigurosa y científica, aspectos culturales concretos, como las relaciones de parentesco y las formas que reviste el intercambio económico entre grupos culturales distintos, mirados éstos desde la perspectiva de la teoría lingüística estructural. En esto último seguirá, a su manera, lo propuesto por Marcel Mauss en su famoso Ensayo sobre los dones (Mauss 1979) Lévi-Strauss interpreta la obra de Mauss "de manera muy personal”, tal como Georges Gurvitch lo señala en el "Prólogo a la primera edición" (Gurvitch: 11-12 1979), entendiendo el sentido del concepto de "acto social total", introducido en la sociología por Mauss, de la siguiente manera: "lo social sólo es real cuando está integrado en un sistema" (Lévi-Strauss 1979: 22). Acerca de la importancia de la aportación de Mauss a las ciencias sociales agrega, más adelante:

Del mismo modo que la fonología para la lingüística, el Essai sur le don inaugura una nueva era para las ciencias sociales. La importancia de este doble acontecimiento (que desgraciadamente Mauss dejó en esquema) puede perfectamente compararse con la importancia del descubrimiento del análisis combinatorio para la matemática moderna $[\ldots]$ En 
determinados campos fundamentales, como es el del parentesco, el de la analogía con el lenguaje, tan repetidamente mantenido por Mauss, ha permitido descubrir las reglas concretas que permiten la creación dentro de cualquier tipo de sociedad de ciclos de reciprocidad cuyas leyes de funcionamiento sean ya conocidas, permitiendo así el empleo del razonamiento deductivo en un campo que parecía sujeto a la arbitrariedad más absoluta (Lévi-Strauss 1979: 31).

Lévi-Strauss encontrará en esas aportaciones el punto de partida fundamental para una teoría general de la comunicación sustentada en el "razonamiento matemático". Lo entiende como un proyecto por realizar:

Por otra parte, al asociarse cada vez más estrechamente con la lingüística, con el fin de crear algún día con ella una amplia ciencia de la comunicación, la antropología social espera beneficiarse de las inmensas perspectivas abiertas a la lingüística, al aplicar el razonamiento matemático al estudio de los fenómenos de la comunicación (Lévi-Strauss 1979: 31-32).

Para lo cual hace referencia a la teoría cibernética de Norbert Wiener, formulada en su obra Cybernetics or Control and Communication in the Animal and the Machine ([1948] 1965) y a la teoría informática de Claude Shannon y Warren Weaver, The Mathematical Theory of Communication (1949). En ésta última se basó Jakobson para construir su propio modelo, no obstante que el asunto primario de la teoría de Shannon y Weaver era la transmisión de señales electromagnéticas de un dispositivo técnico a otro y no la comunicación humana, propiamente dicha. Wiener coincide con el punto de vista de Shannon y Weaver, que más adelante sintetizamos, en cuanto a que los sistemas informáticos no se refieren, específicamente, a la comunicación humana, sino a los dispositivos tecnológicos de intercambio de información entre máquinas:

De lo que generalmente no se da cuenta la gente es de que las rápidamente cambiantes secuencias en una línea telefónica o en un circuito de televisión o en una pieza del aparato de radar, en verdad pertenecen solamente al campo de las estadísticas y de las series temporales, a pesar de que los aparatos por medio de los cuales se combinan y modifican deben 
ser muy rápidos en su acción y, de hecho, deben de ser capaces de presentar resultados pari passu, de acuerdo con las muy rápidas alteraciones del sistema de recepción [...] La cadena de operación tiene que trabajar de manera tan rápida que no admite ningún vínculo humano (Wiener 1965: 60-61 [traducción nuestra]).

El punto de vista de Wiener deja en claro que cualquier extrapolación de tales sistemas a la comunicación humana resulta totalmente inadecuada y arbitraria. En ese sentido, debemos señalar que el punto de partida común de las diversas vertientes teóricas y modelos de la comunicación, formulados a principios de la segunda mitad del siglo Xx, es la teoría de la información desarrollada por Claude Elwood Shannon, en 1948, fue ingeniero electrónico y matemático, presentada en un artículo publicado por la revista de la compañía telefónica Bell, para la cual trabajaba. La intención original de su teoría era la de estudiar las condiciones técnicas de la transmisión de mensajes. No obstante su limitado ámbito de aplicación, la propuesta alcanzó una importante repercusión y terminó siendo elevada al estatuto teórico de paradigma universal de la comunicación a partir de las reflexiones posteriores, agregadas por Weaver, en una extrapolación arbitraria, carente de fundamento.

Originalmente, la teoría se refiere a la transmisión de señales eléctricas y electromagnéticas vía telefónica, radiotelefónica o telegráfica. Su principal objetivo era el de calcular y disminuir los niveles de ruido en la transmisión de información y formaba parte de su investigación tecnológica, orientada a perfeccionar los equipos de telecomunicación de la compañía Bell. Más aún, cuando Shannon habla de información se refiere a un término cuantificable de señales eléctricas cuyo contenido no es importante para la teoría. La cantidad de información trasmitida y recibida se mide por medio de un sistema binario (binary digits), asociado a la velocidad de transmisión. De ahí que, desde el origen, el problema del significado esté totalmente fuera del campo de su investigación, tal como se explica en las primeras páginas: "Los aspectos semánticos de la comunicación son irrelevantes para el problema planteado por la ingeniería. El aspecto significativo consiste en que el mensaje efectivo sea seleccionado de un conjunto de posibles mensajes" (Shannon y Weaver 1949: 3 [traducción nuestra]). 
En 1979 Durand nos prevenía de las consecuencias implícitas en seguir al pie de la letra tales teorías:

Cibernética e informática constituyen las vanguardias victoriosas de las reflexiones lingüísticas y estructurales. A través de un verdadero fenómeno de feed-back, los ordenadores modelan o vuelven a modelar nuestras maneras de pensar. La máquina expresa su más extrema exigencia, que es constreñir al pensamiento al que, no obstante, debe su existencia. De este modo, lo quiera o no, la lingüística moderna contribuye a la edificación de este nuevo universo cibernético en el que la máquina, en cuanto modelo, substituye al hombre (Durand 1993: 40).

Hacía ya quince años, Durand había denunciado el cientificismo imperante en las universidades:

Esta concepción 'semiológica' del mundo será la oficial en las universidades occidentales y en especial en la universidad francesa, hija predilecta de Auguste Comte y nieta de Descartes. No solo el mundo es pasible de exploración científica, sino que la investigación científica es la única con derecho al título desapasionado de conocimiento (Durand 1971: 28).

El señalamiento de Durand, que permite situar al estructuralismo dentro de un conjunto de tendencias del pensamiento de la época (finales de la década de los cincuenta), puede completarse con la siguiente observación de Jean Duvignaud, que reconstruye la situación histórica y la atmósfera intelectual del momento:

En realidad, todo lo que va a definirse bajo el nombre de semiología o de estructuralismo, el recurso exclusivo a la lingüística para construir una ciencia de lo real, todo esto se produce en esa época [...] Semiología y estructuralismo llegan a ser el pensamiento dominante, en circunstancias en que el mundo industrial moderno funciona como una totalidad cerrada de la que cada parte se articula una con otra y en la que los movimientos de rebelión o de transformación acordados se integran en un sistema cada vez más vasto y cada vez más englobante. La "ruptura epistemológica" que permite al estructuralismo ideológico llegar a ser la 
doctrina oficial de la universidad francesa (a tal punto que se ha hablado de un neopositivismo tan imperialista como el de fines del siglo pasado) $\mathrm{y}$ de la intelligentsia misma, es al mismo tiempo una ruptura en un mundo donde las leyes de distribución, de organización, de administración y de tecnoestructura, triunfan sobre las del cambio global (Duvignaud 1977: 190).

Este último autor agrega que en las ciencias sociales y en las humanidades "la búsqueda de la coherencia dominaba sobre la apertura a los elementos imprevisibles de la realidad, y de donde se evacuaba cuidadosamente toda especie de dinamismo colectivo" (1977: 191-192).

Inmerso en esa orientación general del pensamiento dominante de la época, Lévi-Strauss siguió los principios trazados por Trubetzkoy, quien definió a la fonología como "un estructuralismo y un universalismo sistemático". A partir de ésta, Lévi-Strauss buscó encontrar "el juego de leyes generales pero ocultas" (el sistema estructurado), que según él se encontraba detrás de los fenómenos empíricos, dada "la recurrencia, en fin, en regiones del mundo alejadas unas de otras y en sociedades profundamente diferentes, de formas de parentesco, reglas de matrimonio, actitudes entre cierto tipo de parientes, etcétera" (1970:32; véase también: Lévi-Strauss 1985). En función de tal orientación, terminó proponiendo modelos lógico-matemáticos a los cuales, según él, se podían reducir todos los sistemas de parentesco observables en el mundo por la etnografía contemporánea (Lévi-Strauss 1970:29-50).

En relación con ese procedimiento metodológico, Umberto Eco señala:

De las primeras tentativas de las ciencias lingüísticas a las investigaciones de Lévi-Strauss sobre los sistemas de parentesco, el modelo estructural interviene siempre para reducir las experiencias heterogéneas a un razonamiento homogéneo. En este sentido, el modelo se propone como procedimiento operativo, como la única manera posible de reducir a un razonamiento homogéneo la experiencia viva de los objetos distintos. Por ello es una elaboración metalingüística que nos permite hablar de fenómenos de otro orden en términos de sistemas de signos [...] En otros términos, para utilizar correctamente los modelos estructurales no es necesario creer que su elección está determinada por el objeto, sino que es suficiente saber que ha sido elegida por el método (Eco 1994: 344-345). 
En su "Prefacio" a la primera edición de Las estructuras elementales del parentesco, Lévi-Strauss define que "el propósito fundamental de este libro es mostrar que las reglas de matrimonio, la nomenclatura, el sistema de los privilegios y de las prohibiciones, son aspectos inseparables de una misma realidad: la estructura del sistema que se considera" (1985:11). Más adelante afirma que, dentro del conjunto de intercambios que existen entre los grupos sociales, los sistemas matrimoniales, entendidos como "intercambio de mujeres", asumen un carácter universal: "La inclusión de las mujeres en el número de las prestaciones recíprocas de grupo a grupo y de tribu a tribu es una costumbre tan general que un volumen no alcanzaría para enumerar los ejemplos" (1985: 103). ${ }^{1}$

Hacia el final de la obra citada de Lévi-Strauss encontramos las siguientes conclusiones: "De este modo, en el origen de las reglas matrimoniales, incluso de aquellas cuya singularidad aparente pareciera justificarse sólo por medio de una interpretación a la vez especial y arbitraria, siempre encontramos un sistema de intercambio" (1985: 555). Afirma que la ley de la exogamia "es omnipresente, actúa de un modo permanente y continuo [...] Entonces no resulta exagerado decir que es el arquetipo de todas las manifestaciones basadas en la reciprocidad, que proporciona la regla fundamental e inmutable que asegura la existencia del grupo como grupo" (1985: 555).

Finalmente, siguiendo el método de la lingüística estructural —en particular de la fonología de Trubetzkoy -, concluye con relación a las reglas del parentesco y el matrimonio:

Así comprobamos que reglas en apariencia complicadas y arbitrarias podían ser reducidas a un pequeño número de estructuras: sólo hay tres estructuras elementales de parentesco posibles; esas tres se construyen con la ayuda de dos formas de intercambio, y esas dos formas de intercambio dependen a su vez de un solo carácter diferencial: el carácter armónico y no armónico del sistema considerado (1985: 571).

1 Desde mi punto de vista, debería decirse: intercambio de hombres y de mujeres, pues, por ejemplo, en el caso de los matrimonios exogámicos de filiación matrilineal y residencia matrilocal, son los hombres los que viajan a la aldea de la familia de la mujer: son ellos los intercambiados. 
La sorprendente conclusión a la cual arriba Lévi-Strauss es que ¡en todo el mundo, matemáticamente calculdas, sólo pueden existir doce formas posibles de parentesco!

Duvignaud mostrará que, para llegar a la conclusión de la supuesta universalidad de las estructuras elementales del parentesco, el modo de proceder de Lévi-Strauss presenta serios problemas metodológicos:

Se podría hablar aquí de un místico. La afirmación de Lévi-Strauss en Las estructuras elementales del parentesco o en la Antropología estructural se basa sobre una correlación establecida entre la lingüística estructural, la teoría de los conjuntos y algunos casos observados en América del Sur o sacados de los australianos a través de los textos de otros observadores. Se encontraría entonces esta idea fundamental en él, la de que una experiencia bien hecha tiene un valor universal y que, para alcanzar esta universalidad, basta establecer, entre esta observación real y los ejemplos que no conocemos directamente, una relación lógica y probable (Duvignaud 1977: 208).

Al proceder de tal manera, ocurría lo mismo que había sucedido con el hablante en la lingüística estructural: el ser humano vivo y real era expulsado de la antropología. A este respecto y con un claro sentido crítico, unos años más tarde, Duvignaud señaló que los estudios de la antropología estructural sobre cuestiones tales como las relaciones elementales de parentesco nunca nos dicen cómo vive la gente esos sistemas y qué es lo que hace con ellos; "dichas investigaciones dan la impresión de que simplemente se los padece". En realidad, no somos seres pasivos, ya sea por la fuerza o mediante la impugnación o la astucia tenemos la capacidad de actuar sobre estos y adaptarlos a las más diversas situaciones o transformarlos (Duvignaud 1981: 57-59).

Este es el momento para recordar que Giorgio Raimondo Cardona ya había puesto en cuestión el supuesto universalismo de los principios derivados de la lingüística estructural, indicando que en realidad se trataba de generalizaciones que sólo habían tomado en cuenta un grupo lingüístico muy limitado: el indoeuropeo. Desde esta perspectiva previene contra una tradición errónea, inherente a una parte sustantiva de la investigación lingüística: 
La lingüística ha hecho, por su parte, una contribución bastante modesta al desarrollo metodológico de la etnolingüística. La lingüística tiende a transformar en afirmaciones de valor universal reflexiones derivadas de una base empírica muy reducida; es posible que la imagen de la lengua con la que trabaja la lingüística se haya formado partiendo de alguna variedad de las lenguas escritas, literarias o epigráficas [lenguas indoeuropeas] - en el fondo todas homogéneas entre sí- sin consideración ni conocimiento del mundo efectivo de la comunicación lingüística en su contexto. Nunca se podrá censurar suficientemente el etnocentrismo metodológico de la mayor parte de los lingüistas de ayer y hoy (Cardona 1994: 112-113).

En un texto publicado originalmente en 1951 y posteriormente incluido en su Antropología estructural, mismo que se encuentra completamente imbuido de su obsesión de cientificidad, Lévi-Strauss llega a enunciar proposiciones que hoy me parecen francamente aberrantes (1970: 51-61). Afirma que: "Numerosos problemas lingüísticos pertenecen al dominio de las modernas computadoras". Por lo cual, proporcionando los debidos elementos y reglas combinatorias fonológicas: "Se obtendría así una especie de tabla periódica de las estructuras linguiísticas, comparable a la tabla de los elementos que la química moderna debe a Mendeliev" (Lévi-Strauss 1970:53). Más adelante afirma, siguiendo una hipótesis de Jakobson sobre la variedad de estructuras fonológicas empleadas en una lengua - la cual ha sido criticada por su reduccionismo-, que el conjunto de relaciones de todas éstas daría la "metaestructura" de dicha lengua, que sería la "ley del grupo" y que ésta podía ser revelada mediante el uso de una calculadora y los métodos matemáticos conocidos (Lévi-Strauss 1970: 53-54).

Concluye que, desde esta perspectiva, sería posible llevar a cabo el análisis estructural y comparado de todos los elementos que componen una cultura (costumbres, instituciones, conductas):

Estaríamos en condiciones de comprender ciertas analogías fundamentales entre manifestaciones de la vida en sociedad muy alejadas en apariencia unas de otras, como el lenguaje, el arte, la religión. Al mismo tiempo, en fin, cabría la posibilidad de superar algún día la antinomia entre la cultura, que es cosa colectiva, y los individuos que la encarnan puesto 
que en esta nueva perspectiva comprendida la pretendida "conciencia colectiva" se reduciría a una expresión, en el plano del pensamiento y las conductas individuales, de ciertas modalidades temporales de las leyes universales en que consiste la actividad inconsciente del espíritu (LéviStrauss 1970:61).

En primer lugar, podemos señalar al respecto que, tal como observa Ricoeur, para lograr llegar por un procedimiento lógico a la homología de semejanzas entre los diversos sistemas, resulta necesario reducir la semejanza, tal como el mismo Lévi-Strauss lo admite: el nivel lógico se alcanza por empobrecimiento semántico, se hace posible sólo mediante un empobrecimiento sustantivo de los significados concretos, culturalmente elaborados y sujetos a la innovación, así como a la variabilidad temporal. En segundo lugar, la hipótesis resulta verdaderamente arriesgada, y tal como lo destaca Eco, implica la reducción de reducciones, es decir, implica convertir todos los sistemas de códigos culturales en un solo megasistema unificado, dentro del cual las correspondencias entre elementos de cada sistema (sistema de la lengua, sistema del parentesco, sistema económico, sistema mitológico, sistema artístico) son perfectamente homologables entre sí, término a término. Lo que resulta prácticamente imposible, aun tratándose de sistemas abstractos, totalmente formalizados. Tal correspondencia entre sistemas se queda en el nivel de los deseos del autor, por no decir en el mundo de la ciencia ficción. Así cuestiona Eco las posibilidades reales de tal proposición:

Para que estas transformaciones sean posibles [la transformación de modelos de un sistema a otro] se necesita una garantía para la operación, garantía que facilita la elaboración de un sistema de sistemas. En otros términos, si existe un sistema de reglas que permite la articulación de los intercambios de parentesco como modos de comunicación (código del parentesco), ha de existir un sistema de reglas que prescriba la equivalencia entre el signo lingüístico y el signo del parentesco, estableciendo su equivalencia formal, el mismo valor posicional de los signos, término por término. Este sistema será el que, para utilizar un término que no utiliza nuestro autor, llamaremos metacódigo, en el sentido que es un código que permite definir y nombrar otros códigos subyacentes (1994: 348). 
La anterior verificación resulta indispensable, pues tal reducción resulta imposible y estamos frente al límite del estructuralismo, en el sentido mostrado por Ricoeur: "la conciencia de la validez de un método nunca puede ser separada de la conciencia de sus límites" (Ricoeur 2003: 34). En particular, sobre el método estructural señala:

Las cosas se complican con el arte y la religión; aquí, ya no tenemos "una especie de lenguaje", como en el caso de las reglas del matrimonio y de los sistemas del parentesco, sino un discurso significante, edificado sobre la base del lenguaje, considerado como instrumento de comunicación; la analogía se desplaza hacia el interior mismo del lenguaje y pasa a referirse a la estructura de tal o cual discurso particular, estructura que, a su vez, será comparada con la estructura general de la lengua. Por lo tanto, no es cierto a priori que la relación entre diacronía y sincronía, válida en lingüística general, rija de manera tan dominante la estructura de los discursos particulares (Ricoeur 2003: 40).

\section{Las raíces positivistas y cartesianas \\ del estructuralismo de Lévi-Strauss}

En función de lo expuesto anteriormente, a partir de las proposiciones de Lévi-Strauss podemos derivar un conjunto de conclusiones que nos permiten comprender el sentido y las consecuencias del proyecto científico que dará forma a todo el proyecto teórico que se deriva de las premisas expuestas en su Antropología estructural. En primer término podemos observar con claridad que Lévi-Strauss parte del supuesto de que lo que puede otorgar un estatuto científico a la antropología es no sólo la introducción de los métodos propios de la fonología universalista y estructuralista, así como de las "leyes universales del intercambio" provenientes de Mauss, sino, de manera explícita, el método de las ciencias naturales. Así, afirma que en el "plano "microsociológico" se esperará encontrar las leyes de estructura más generales, como el lingüista descubre las suyas en el plano infrafonémico o el físico en el plano inframolecular, es decir, en el nivel del átomo (Lévi-Strauss 1970: 33).

Para él, se trata de encontrar leyes generales - del tipo de las que enuncian ciencias como la física-, para lo cual es necesario que los 
matices concretos que asumen dentro de cada grupo cultural específico las relaciones de parentesco, tal como éstas son registradas en los documentos y testimonios etnográficos, sean eliminados y reducidos a sistemas, a modelos matemáticos abstractos que sinteticen sus características más generales, borrando toda huella cultural concreta. Como veremos más adelante, al proceder de esa manera, se suprimen por completo el método y la finalidad particulares de la etnografía: la descripción detallada del carácter cultural específico de cada sociedad estudiada o, en palabras de Geertz (1997), la descripción densa.

Su Antropología estructural se inscribe, así, en la orientación general que fue característica del positivismo comteano, el cual buscaba la construcción de una filosofía positiva, realista, según Comte, una filosofía sustentada en la ciencia, en cuya base estarían las matemáticas y en cuya cúspide la sociología. Ya sostenía el filósofo en su Curso que el carácter fundamental de la filosofía positiva radicaba en considerar a todos los fenómenos como sujetos a leyes naturales invariables y cuyo descubrimiento y reducción al menor número posible constituían su finalidad (Comte 2004: 30). "Ahora que el espíritu humano ha fundado la física celeste, la física terrestre mecánica o química, la física orgánica, vegetal o animal, le falta completar el sistema de las ciencias de la observación fundando la física social. Ésta es la más grande y apremiante necesidad de nuestra inteligencia" (2004: 37). Plantea que la física social consuma el proyecto de la filosofía positiva: "la constitución de la física social, completando al fin el sistema de las ciencias naturales, hace posible, e incluso necesario, poder resumir los diversos conocimientos adquiridos, alcanzando ahora un estado fijo y homogéneo, para coordinarlos, mostrándolos como ramas diversas de un sistema único" (2004: 39).

Sin embargo, diremos que el verdadero origen de una intención de cientificidad, como la de Lévi-Strauss, puede rastrearse aún más atrás, la hallamos en René Descartes por su manera de concebir la mathesis universalis, esbozada en sus Reglas para la dirección del espíritu ([1701] 1971), así como en su célebre Discurso del método ([1637] 1993). Tal como queda enunciado con toda claridad en la segunda regla: "Debemos ocuparnos solamente de aquellos objetos que pueden ser conocidos por nuestro espíritu de un modo cierto e indubitable" (Descar- 
tes 1971: 110). Para el filósofo, éste conocimiento radica, precisamente, en las matemáticas:

Por esta regla rechazamos los conocimientos probables y establecemos el principio de que sólo debemos aceptar los conocimientos ciertos y que no dejen lugar a la más pequeña duda [...] Si nuestro cálculo es exacto, de todas las ciencias conocidas, sólo al estudio de la aritmética y la geometría, nos lleva la observación de esta regla (Descartes 1971: 111).

Por esta razón Durand afirmará que "lo que instaura Descartes es, en verdad, el 'reino' del algoritmo matemático" (Durand 1971: 27). Si entendemos que el algoritmo es un conjunto pre-escrito de instrucciones o reglas bien definidas, ordenadas y finitas que permite realizar una actividad mediante pasos sucesivos que no generen dudas a quien deba realizar dicha actividad, comprenderemos con claridad lo que Durand nos quiere decir.

Heidegger desarrollará el asunto en sus múltiples consecuencias. De acuerdo con él, en las Reglas de Descartes nos topamos con "una fundamentación de lo matemático para que se convierta en una norma para el espíritu investigador", más aún, en una norma para todo pensar (Heidegger 2009: 131). Agrega que en dicho texto "se acuña el concepto moderno de "ciencia" (Heidegger 2009:131). La conclusión a la que llega Heidegger es contundente: "Ponemos un título a este carácter fundamental de la actitud cognoscitiva moderna si decimos que la nueva pretensión de saber es la pretensión de saber matemática" (2009:96-97).

Precisamente esto es lo que leemos en la "Regla IV", en donde Descartes afirma:

Reflexionando sobre esto más atentamente descubro que debemos referir a las matemáticas todas las cosas en que se examina el orden o la medida, importando poco se trate de números, figuras, astros, sonidos o de cualquier otro objeto si se investiga esa medida u orden. Debe, pues, existir una ciencia general que explique todo lo que podemos conocer relativo al orden y a la medida sin aplicación a ninguna materia especial. La denominación de esta ciencia no consiste en un nombre extranjero, sino en el antiguo y usual de matemáticas universales, porque contiene todos los elementos que han hecho llamar a las otras ciencias, partes de las matemáticas (Descartes 1971: 119). 
Para poner de manifiesto el problema implicado en este asunto, Heidegger nos remonta a la etimología griega de la palabra: "Lo matemáti-

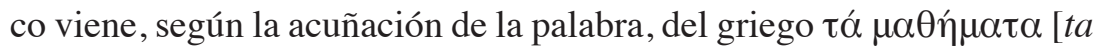

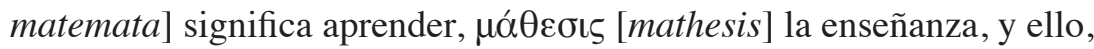
además, en un doble sentido: enseñanza como acudir a la enseñanza y aprender y, por otro lado, enseñanza como aquello que es enseñado" (Heidegger 2009: 98).

De tal suerte, distingue las matemáticas de lo matemático y concluye que tomar conocimiento de las cosas es la esencia propia del aprender,

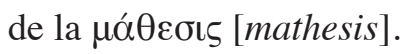

Nuestra expresión "lo matemático" tiene siempre este doble sentido; mienta en primer lugar lo aprehensible en el modo caracterizado y sólo en él; y, en segundo lugar, el modo mismo de aprender y proceder. Lo matemático es aquello abierto en las cosas en lo que ya nos movemos siempre y a partir del cual tenemos experiencia de ellas en general como cosas y como tales cosas. Lo matemático es aquella posición fundamental ante las cosas en la que nosotros tomamos previamente las cosas en relación con cómo nos son, necesitan ser y deben ser ya dadas. Lo matemático es por eso el presupuesto fundamental de las cosas (Heidegger 2009: 104).

Así, entendemos que la reducción de lo matemático a las matemáticas es un producto de la metafísica moderna que se inicia con Descartes y, a la vez, de una larga y continuada tergiversación de la noción griega antigua. Heidegger aclara que: "su esencia no reside en el número como delimitación pura de la pura cantidad, sino a la inversa: sólo porque el número pertenece a tal esencia, pertenece también a lo aprehensible en el sentido de la $\mu$ á $\theta \eta \sigma \iota \varsigma$ [mathesis]" (Heidegger 2009:104). Concluye: "Por lo dicho, esto no puede querer decir que la ciencia trabaje con la matemática, sino que, más bien, ha preguntado de un modo que tuvo como consecuencia que por primera vez entrara en juego la matemática en sentido restringido" (Heidegger 2009: 105).

En esta cuestión podemos destacar el contraste entre dos puntos de vista. El primero es el de Comte, que lo entiende como la consolidación de un largo proceso que parte de Aristóteles y la Escuela de Alejandría, pasa por la introducción de las ciencias naturales, por los árabes en la Europa occidental durante la Edad Media y continúa en la modernidad: 
Sin embargo, por fijar un momento más preciso y evitar así las divagaciones, señalaré esta fecha, hace dos siglos, en que la acción combinada de los principios de Bacon, de las teorías de Descartes y de los descubrimientos de Galileo, hizo que el espíritu de la filosofía positiva comenzara a erigirse en el mundo en clara oposición al espíritu teológico y metafísico. A partir de ese momento, las concepciones positivas se separaron completamente de la alianza supersticiosa y escolástica que más o menos viciaba el auténtico carácter de todos los trabajos anteriores.

A partir de esa época gloriosa, el movimiento ascendente de la filosofía positiva y el descendente de la filosofía teológica y la metafísica han sido extremadamente relevantes (Comte 2004: 34-35).

El segundo punto de vista es el de Heidegger, quien mira el mismo proceso desde una perspectiva crítica:

Ahora bien, la ciencia moderna, a diferencia de las invenciones conceptuales meramente dialécticas de la ciencia medieval y la escolástica, debía fundarse en la experiencia. Y en vez de eso, coloca en primer plano un principio que refiere una cosa que no existe. Exige una representación fundamental de las cosas que contradice la representación común.

En esta pretensión se fundamenta lo matemático, es decir la imposición de una determinación de la cosa que no está generada desde ésta misma de modo acorde a la experiencia y que, igualmente, subyace a todas las determinaciones de las cosas, las posibilita y les abre un espacio. Una tal concepción fundamental de las cosas no es arbitraria ni de suyo obvia. Por eso se precisó de una larga disputa para convertirla en la dominante. Fue necesaria una transformación de la manera de acceder a las cosas, junto con la forja de un nuevo modo de pensamiento (2009:116).

De tal suerte que "la ciencia moderna es experimental sobre el fundamento de la proyección matemática. El impulso experimental hacia las cosas es una consecuencia necesaria del propio sobrepasar matemático, que pasa por alto todos los hechos. Sin embargo, donde este sobrepasar en la proyección se clausura o se agota, los hechos son meramente constatados y surge el positivismo" (Heidegger 2009: 120). Esto, además, da lugar a la hipóstasis de lo matemático por lo verdadero: "En la proyección matemática se consuma la vinculación a los principios 
exigidos por ella misma. Según esta tendencia interna de la liberación para una nueva libertad, lo matemático impulsa desde sí a poner su propia esencia como fundamento de sí mismo y, con ello, de todo saber" (Heidegger 2009: 117).

A partir de esta muy breve exposición del asunto podemos concluir que la propuesta de la antropología estructural se refiere a lo que podemos denominar, desde la crítica heideggeriana y los desarrollos posteriores de la antropología, una cosa que no existe, es decir, se refiere a representaciones, a abstracciones que no tienen como sustento la experiencia; se reduce a meros modelos lógico-matemáticos que eliminan por completo el modo de conocer propio de la etnografía, que consiste en la descripción densa de los fenómenos culturales concretos. En un sentido crítico respecto de lo que propone Lévi-Strauss, Duvignaud afirmará: "no hablamos de las cosas, no las conocemos en sí mismas nombrándolas: esta ontología, ingenua pero que ocupa el idealismo occidental, no tiene ningún sentido, o no tiene más sentido; hablamos de lo que se constituye en el interior de nuestro sistema de lenguaje" (1977: 208). Por tal razón propone un sentido distinto para la antropología:

La embriología de la antropología es tanto más necesaria de establecer cuanto se pretende hacer de ella un simple lenguaje científico despojado de toda realidad concreta.

Esta "iluminación" conduce al ejercicio del encuentro de hombres a los que no basta reconocer el carácter de "diferencia", ni enunciar el sistema cultural que dirige sus relaciones mutuas para agotar su sentido, ni su infinita riqueza. A partir del momento en que se admite la evidencia de la existencia colectiva de otros grupos humanos, lo que construimos en Europa se convierte en objeto de un sujeto hasta ese momento silencioso o mudo: si la antropología tiene un sentido, consiste en dar su lenguaje perdido a las sociedades diferentes [...] (Duvignaud 1977:44-45).

Coincidentemente, Durand nos mostrará que en las sociedades tradicionales se vive un complejo pluralismo simbólico en todos los aspectos de su cultura, todo intento de reducirlo a sistemas formales y a modelos lógico-matemáticos va en contra del sentido que asumen dentro de su propia vida cultural: 
Y, sin embargo, el etnógrafo o el etnólogo no pueden permanecer insensibles a la gran cantidad de sustancia mitológica, poética, simbólica, que reina en estas sociedades llamadas "primitivas". Estas sociedades parecen suplir la falta de progreso tecnológico, la carencia de preocupaciones tecnocráticas, con una fantástica profusión imaginativa. Los actos más cotidianos, las costumbres, las relaciones sociales, están sobrecargadas de símbolos, son duplicados en todos sus detalles por todo un cortejo de valores simbólicos (1971: 56).

Sobre este mismo punto del método etnográfico, rescato esta reflexión de Clifford Geertz que me parece decisiva:

El problema metodológico que presenta la naturaleza microscópica de la etnografía es real y de peso [...] Como es inseparable de los hechos que presenta la descripción densa, la libertad de la teoría para forjarse de conformidad con su lógica interna es bastante limitada. Las generalidades a las que logra llegar se deben a la delicadeza de sus distinciones, no a la fuerza de sus abstracciones (1997: 34-35).

Para él "la tarea esencial de la elaboración de una teoría [cultural] es, no codificar regularidades abstractas, sino hacer posible la descripción densa, no generalizar a partir de casos particulares sino generalizar dentro de éstos" (Geertz 1997: 36).

Geertz continúa señalando que, a pesar de que todo trabajo de descripción densa se inicia "partiendo de un estado general de desconcierto", éste no comienza ni se desarrolla "con las manos intelectualmente vacías" (1997: 37). Es evidente que aquí no se trata de la idea ingenua de que es posible una pura descripción neutra de los fenómenos culturales observados por la etnografía; a lo largo de su obra el mismo Geertz se ha encargado de poner de manifiesto los problemas de interpretación que plantea de suyo el quehacer antropológico (véase Geertz 2000 y 2001).

La hermenéutica filosófica nos ha enseñado con toda claridad y precisión que la subjetividad y la historicidad son componentes irreducibles del discurso y, por ello, del trabajo interpretativo de todo fenómeno social o natural. Inevitablemente, en todo proceso de interpretación, el intérprete proyecta sus categorías de pensamiento, así como su subje- 
tividad sobre lo interpretado (Gadamer 1999: 331-377). El intérprete "realiza siempre un proyectar", proyecta un sentido preexistente sobre lo que interpreta, sentido que está determinado por su horizonte cultural (Gadamer 1999: 333). En esa línea de reflexión, Gadamer sigue lo ya expuesto por Heidegger en El ser y el tiempo:

La interpretación se funda en todos los casos en un "ver previo" que "recorta" lo tomado en el "tener previo" de acuerdo con una determinada posibilidad de interpretación. Lo comprendido tenido en el "tener previo" y visto en el "ver previo" se vuelve, por obra de la interpretación, concebible. La interpretación puede sacar del ente mismo que se trata de interpretar los conceptos correspondientes, o bien forzar al ente a entrar en conceptos en los que se resiste a entrar por su forma de ser. Como quiera que sea, la interpretación se ha decidido en cada caso ya, definitivamente o con reservas, por unos determinados conceptos; se funda en un "concebir previo" (Heidegger 2008: 168).

Lo anterior termina de cobrar sentido cuando Heidegger concluye que "toda interpretación que haya de acarrear comprensión tiene que haber comprendido ya lo que trate de interpretar" (2008: 170). Concluimos así que la objetividad y la neutralidad absolutas no existen en las ciencias humanas ni en las llamadas "ciencias duras" (Duch et al. 2008: 171). LéviStrauss parece ignorar estas consideraciones básicas cuando afirma que:

en lingüística se puede, entonces, afirmar que la influencia del observador sobre el objeto de observación es despreciable: no basta que el observador tome conciencia del fenómeno para que éste se modifique a causa de ello [...] El lenguaje es, pues, un fenómeno social que constituye un objeto independiente del observador y para el cual se poseen largas series estadísticas (Lévi-Strauss 1970: 52-53).

\section{Diferencias entre las ciencias naturales y las ciencias del espíritu}

Volviendo a la etnografía, respecto del proyecto de Lévi-Strauss, y siguiendo a Geertz, podemos señalar críticamente que, en el caso de la 
antropología, así como en el de todo el conjunto de las ciencias sociales y de las humanidades, no nos hallamos frente a ciencias que elaboren leyes universales, sino frente a ciencias que ponen de manifiesto significados concretos: "el análisis de la cultura ha de ser [...] no una ciencia experimental en busca de leyes, sino una ciencia interpretativa en busca de significaciones" (Geertz 1997: 20). La cultura "denota un esquema históricamente transmitido de significaciones representadas en símbolos, un sistema de concepciones heredadas y expresadas en formas simbólicas por medio de los cuales los hombres comunican, perpetúan y desarrollan su conocimiento y sus actitudes frente a la vida" (Geertz 1997: 88).

Esta distinción básica entre ciencias naturales y ciencias del espíritu, que el mismo Lévi-Strauss no ignora pero que interpreta de otra manera, es fundamental para comprender el equívoco cientificista del que parte, tanto al sostener que, en el ámbito de las ciencias sociales y las humanidades, el observador no afecta lo observado - un objetivismo ingenuo-, así como al proponer que se dote de cientificidad a la antropología por medio de la introducción de procedimientos lógicomatemáticos de abstracción, gracias a los cuales sería posible llegar al descubrimiento de las leyes generales ocultas que rigen el comportamiento humano universal, métodos que siguen el modelo de las matemáticas modernas (Lévi-Strauss 1979: 24-27).

Queda de manifiesto la arbitrariedad de la extrapolación de los métodos de las ciencias naturales a la etnografía cuando Lévi-Strauss pretende completar y explicar mitos de una región del mundo a partir de otros que pertenecen a tradiciones culturales totalmente distintas. Sobre todo cuando se supone, desde su punto de vista, que los sistemas sociales, como la mitología, constituyen estructuras unitarias, cerradas y autosuficientes, como la lengua, las partes del sistema deberían poderse explicar por sus relaciones internas, sin necesidad de recurrir a sistemas externos pertenecientes a otras tradiciones culturales. Así, sorprende la afirmación que aparece en el "Prefacio" de Mitológicas III, que justifica su modo de proceder:

Esta validación a distancia, por mitos procedentes de poblaciones muy diversas y alejadas unas de otras, y por giros figurados de nuestro len- 
guaje popular (pero que cualquier otra lengua ilustraría del mismo modo o de otros), nos aparece como un modo de prueba etnográfica (que no es indigno de los que utilizan ciencias más adelantadas). En efecto, se afirma con frecuencia que a diferencia de las ciencias humanas, las ciencias de la naturaleza poseen, ellas solas, el privilegio de poder renovar sus experiencias en condiciones idénticas en otros lugares y en otros momentos. Ni hay que decir que no preparamos nuestras experiencias, pero el despliegue múltiple de las culturas humanas permite buscarlas donde estén (Lévi-Strauss 1981: 5).

En términos metodológicos, tal procedimiento carece por completo de rigor. En primer lugar debido a la diferencia sustantiva que existe en los modos de operar de los dos tipos de ciencia: las naturales pueden reproducir en condiciones idénticas sus experiencias, pues se trata de experiencias en las cuales las variables son aisladas artificialmente en laboratorio, dado su carácter experimental, algo que es imposible lograr en las ciencias sociales y en las humanidades.

En segundo lugar, los estudios de mitología comparada sólo tienen validez relativa si se establecen con claridad los aspectos a comparar, tomando siempre en consideración los campos semánticos y los campos prácticos a los que pertenecen tales aspectos o fragmentos y con los cuales se asocian, respetando con todo cuidado los significados culturales específicos que se les asignan en cada caso, de acuerdo con un método de documentación etnográfica y etnohistórica serio y sistemático. De otra manera, se compararían arbitrariamente cuestiones que no tienen nada que ver entre sí y que pertenecen a campos semánticos y a prácticas sociales totalmente distintos, cancelándose la validez, ya sea de la comparación o de la sustitución.

Así, por ejemplo, en Mitológicas III se vale de mitos que considera semejantes a los que estudia, provenientes de otras tradiciones y comenta al respecto: "Estas versiones son interesantes, pero complican el problema en vez de simplificarlo. En efecto, corresponden a un conjunto mitológico atestiguado desde el Círculo Ártico hasta Tierra del Fuego" (Lévi-Strauss 1981: 38). Tal procedimiento ya era común desde el primer volumen de Mitológicas, cuando el autor se valía de mitos provenientes de las tradiciones ojibwa de Canadá y los Estados Unidos y de los tikopia de las islas del Pacífico suroeste, en Oceanía, para expli- 
car mitos de los bororo de Brasil central en Sudamérica (Lévi-Strauss 1996: 58-61).

Específicamente sobre este aspecto del método de Lévi-Strauss para abordar el estudio del mito, Duvignaud señala críticamente:

Los fenómenos de los que estamos hablando exigen una epistemología nueva [...] Tomemos un problema: el de los mitos, por ejemplo. En ese respecto rechazamos un método como el de Lévi-Strauss que consiste en separar lo mítico de lo existencial y de las prácticas materiales. Siento un profundo respeto por Lévi-Strauss, pero algo así como "la mitología reconstituida de la indianidad, de los esquimales a las tribus del sur de Chile", es absolutamente indiferente a la realidad actual de las sociedades de las que habla, pues entonces: viva el mito y mueran los hombres.

Lo que nosotros hemos hecho es investigar, haciendo uso de una epistemología que se define en la acción misma: sitúa las prácticas en su contexto y comprende que cada práctica supone un aparato de mitos, de creencias, de afectos; es éste conjunto, como un todo, el que hay que entender (Duvignaud 1981: 61-65).

Así, el proceder de Lévi-Strauss, que aplica los principios de método de las ciencias naturales a la etnografía, me parece francamente arbitrario e infundado. Para su crítica apelo al punto de vista de Gadamer, quien ha desarrollado ya este asunto con todas sus consecuencias, mostrando que "en las ciencias del espíritu no puede hablarse de un 'objeto idéntico' de la investigación, del mismo modo que en las ciencias de la naturaleza" (1999: 353). El mismo autor demostrará que

La investigación histórica está soportada por el movimiento histórico en que se encuentra la vida misma, y no puede ser comprendida teleológicamente desde el objeto al que se orienta la investigación. Incluso ni siquiera existe realmente tal objeto. Es esto lo que distingue a las ciencias del espíritu de las de la naturaleza. Mientras que el objeto de las ciencias naturales puede determinarse idealiter como aquello que sería conocido en un conocimiento completo de la naturaleza, carece de sentido hablar de un conocimiento completo de la historia. Y por eso no es adecuado en último extremo hablar de un objeto en sí hacia el que se orientase esta investigación (Gadamer 1999: 353). 
Para completar la argumentación que permite distinguir a un tipo de ciencia de la otra, Gadamer abunda en el asunto: "el verdadero problema que plantean las ciencias del espíritu al pensamiento es que su esencia no queda correctamente aprehendida si se las mide según el patrón del conocimiento progresivo de leyes. La experiencia del mundo sociohistórico no se eleva a ciencia por el procedimiento inductivo de las ciencias naturales" (Gadamer 1999: 32). Concluye:

Su idea es más bien comprender el fenómeno mismo en su concreción histórica y única. Por mucho que opere en esto la experiencia general, el objetivo no es confirmar y ampliar las experiencias generales para alcanzar el conocimiento de una ley de tipo de cómo se desarrollan los hombres, los pueblos, los estados, sino comprender cómo es tal hombre, tal pueblo, tal estado, qué se ha hecho de él, o formulado muy generalmente, cómo ha podido ocurrir que sea así (1999: 33).

Hacia finales del siglo XIX, en su Introducción a las ciencias del espíritu (1883), Wilhelm Dilthey fue el primero en establecer con suma claridad, desde una perspectiva hermenéutica, la distinción entre las ciencias del espíritu y las ciencias naturales: "Las ciencias del espíritu no constituyen un todo con una estructura lógica que sería análoga a la articulación que nos ofrece el conocimiento natural; su conexión se ha desarrollado de otra manera y es menester considerar cómo ha crecido históricamente" (Dilthey 1978: 32). Justo al comienzo de su exposición, Dilthey se distancia críticamente del positivismo:

Estos hechos espirituales que se han desarrollado en el hombre históricamente y a los que el uso común del lenguaje conoce con el nombre de ciencias del hombre, de la historia, de la sociedad, constituyen la realidad que nosotros tratamos, no de dominar, sino de comprender previamente. El método empírico exige que la cuestión del valor de los diversos procedimientos de que el pensamiento se sirve para resolver sus tareas se decida histórico-críticamente dentro del cuerpo de esas mismas ciencias, y que se esclarezca mediante la consideración de ese gran proceso cuyo sujeto es la humanidad misma, la naturaleza del saber y el conocer en ese dominio. Semejante método se halla en oposición con otro que recientemente se practica con excesiva frecuencia por los lla- 
mados positivistas, y que consiste en deducir el concepto de ciencia de la determinación conceptual obtenida en el trabajo de las ciencias de la naturaleza, resolviendo luego con ese patrón qué actividades intelectuales merecen el nombre y rango de ciencia (Dilthey 1978: 13).

En su Historia de la hermenéutica, Maurizio Ferraris sintetiza de manera muy lograda la argumentación de Dilthey:

Dilthey tematiza aquí la distinción entre las ciencias del espíritu y las ciencias de la naturaleza, que se funda ya sobre la diferencia entre los objetos de estudio de los dos tipos de saber (las ciencias de la naturaleza se ocupan de fenómenos externos al hombre, mientras las ciencias del espíritu estudian un campo del cual el hombre forma parte) o sobre las diferentes modalidades cognoscitivas, por las cuales, mientras el saber de las ciencias naturales viene de la observación del mundo externo, el de las ciencias del espíritu es extraído de una vivencia (Erlebnis), en la cual el acto de conocer no es distinto del objeto conocido. Mientras en las Naturwissenschaften, la observación del fenómeno se separa de las propiedades específicas del fenómeno mismo, en las Geisteswissenschaften, el conocimiento vital de un sentimiento interno se identifica con (o mejor es) aquel sentimiento. Asimismo, mientras las primeras se avalan con explicaciones causales, las segundas utilizan categorías axiológicas o teleológicas diferentes, tales como significado, fin, valor (y mientras la explicación causal no modifica la sustancia del fenómeno, la comprensión de los significados asume y transforma el “objeto” estudiado) (2002: 132).

Para matizar en profundidad la afirmación de Dilthey, faltaría, desde un punto de vista hermenéutico, constatar que la perspectiva epistémica de las ciencias naturales no está del todo exenta de juicios de valor y que es el propio modo de pensar de una época el que, subrepticiamente, se infiltra en el discurso de las ciencias naturales. Heidegger lo muestra de esta forma: "La situación de una ciencia en cada momento responde al estatuto concreto de las cosas. El mostrarse de éstas puede que resulte ser un aspecto tan asentado por la tradición que ni siquiera sea posible reconocer lo que de impropio tiene, y se lo tenga por verdadero" (Heidegger 2000: 99; véase también: Dilthey 1978: 333-384). De ahí que proponga: "Hay que desmontar la tradición. Sólo de esa manera resultará posible un planteamiento original del asunto" (Heidegger 2000: 99). 


\section{El trasfondo metafísico del método estructural}

Anteriormente habíamos visto la manera en la cual Lévi-Strauss llega a la reducción de reducciones afirmando que sería posible llevar a cabo el análisis estructural y comparado de todos los elementos que componen una cultura (costumbres, instituciones, conductas), así como las implicaciones que tal afirmación supone, tal como Eco las pone de manifiesto de manera crítica; es decir, hipotéticamente sería posible equiparar, término a término, los elementos de todos los sistemas de códigos que componen una cultura, siendo posible hallar las equivalencias de uno a otro. Esto resulta, tanto para Eco como para mí, imposible. En dado caso se trataría de "elaborar transformaciones cada vez más complejas con cuyos modelos se puedan explicar los fenómenos más disformes [...] a falta de una verdad de hecho tenemos una verdad de razón" (Eco, 1994: 348). Y, aunque en términos de rigor lógico el razonamiento parece impecable, dice Eco, lo que se deja ver es una filosofía que en el fondo afirma "la existencia de mecanismos universales de pensamiento, y como consecuencia, la universalidad de la naturaleza humana" (Eco 1994: 349). De tal suerte, con lo que nos topamos es con el "paso de una concepción operativa a una concepción substancialista: los modelos elaborados como universales, funcionan universalmente, por lo tanto, reflejan una substancia universal que los garantiza" (Eco, 1994: 349).

En el fondo, dirá Eco, "El tejido conectivo de toda investigación estructural es el mismo en todo comportamiento primitivo o civilizado: es la presencia de un pensamiento objetivo" (1994: 350). Esto queda de manifiesto en la Antropología estructural, esa sustancia universal se deriva de "la actividad inconsciente del espíritu":

De todos los fenómenos sociales, el lenguaje es el único que hoy parece susceptible de un estudio verdaderamente científico que nos explique la manera en que se ha formado y que prevea ciertas modalidades de su evolución ulterior. Estos resultados son posibles gracias a la fonología y en la medida en que ella ha sabido, más allá de las manifestaciones conscientes e históricas de la lengua, que son siempre superficiales, alcanzar realidades objetivas. Éstas consisten en sistemas de relaciones, que son a su vez producto de la actividad inconsciente del espíritu (Lévi-Strauss 1970: 54). 
Como bien señala Eco, Lévi-Strauss termina afirmando que la lengua y la cultura son expresiones paralelas de algo más fundamental que es el espíritu humano, y que existe una identidad "entre las leyes del mundo y las leyes del pensamiento" (Eco 1994: 350-351). Al final, Lévi-Strauss sostendrá, al contestar afirmativamente a la pregunta que él mismo se ha formulado, que "[las] diversas formas de la vida social son sustancialmente de una misma naturaleza: sistemas de conducta cada uno de los cuales son una proyección, sobre el plano del pensamiento consciente y socializado, de leyes universales que rigen la actividad inconsciente del espíritu" (Lévi-Strauss 1970: 54). De la premisa anterior podemos, con toda justicia, deducir lógicamente, que toda actividad social, así como toda producción cultural tienen su origen y fundamento en "leyes universales que rigen la actividad inconsciente del espíritu" y que esas leyes son objetivas. Por ser inconsciente y ahistórico, este espíritu resulta ser el inverso gemelo (negativo) del espíritu absoluto hegeliano: "El espíritu es, pues, [dirá Hegel] conciencia en general, que abarca en sí la certeza sensible, la percepción y el entendimiento, en tanto que el espíritu, en el análisis de sí mismo, retiene el momento según el cual es él mismo realidad objetiva que es y hace abstracción de que esta realidad es su propio ser para sî" (Hegel, 1973: 260).

Ricoeur señala que las "leyes lingüísticas", de las que habla Lévi-Strauss,

[...] designan un nivel inconsciente del espíritu y, en ese sentido, no reflexivo, no histórico; este inconsciente no es el inconsciente freudiano de la pulsión, del deseo, en su facultad de simbolización. Se trata de un inconsciente más kantiano que freudiano, un inconsciente categorial, combinatorio; es un orden finito o el finitismo del orden, pero tal que se ignora a sí mismo. Hablo de inconsciente kantiano solamente por considerar su organización, pues se trata más bien de un sistema categorial sin referencia a un sujeto pensante; por esa razón, el estructuralismo, como filosofía, desarrollará una clase de intelectualismo profundamente antirreflexivo, antiidealista, antifenomenológico; pero, además, ese espíritu inconsciente puede ser considerado como análogo a la naturaleza; es más, quizás sea la naturaleza (Ricoeur 2003: 36).

Aplicado al estudio de los mitos, Eco vislumbra las consecuencias del fundamento último del método lévi-straussiano: 
Así pues, ¿qué quiere decir estudiar los mitos? Quiere decir individualizar un sistema de transformaciones de mito a mito que demuestre que en cada una de ellas se recorren algunos caminos fundamentales del pensamiento, lo sepan o no los constructores de mitos. Sea lo que fuere que los mitos pretenden narrar, siempre repiten la misma historia. Y esta historia es la exposición de las leyes del espíritu en que se basan. No son los hombres que piensan los mitos, sino que los mitos se piensan en los hombres. Mejor aún, en el juego de posibles transformaciones recíprocas, los mitos se piensan entre ellos (1994: 351-352).

\section{La infundada crítica de Lévi-Strauss \\ al concepto junguiano de arquetipo}

Sorprende que, tal como hemos visto en el apartado anterior, todo el supuesto rigor científico del complejo aparato teórico de Lévi-Strauss termine dependiendo de un concepto tan poco fundamentado como lo es el "carácter objetivo" de "la actividad inconsciente del espíritu humano" como trasfondo y basamento último de toda cultura, pues entiende tanto el uso de la lengua como toda práctica cultural, teniendo un carácter esencialmente inconsciente que obedece a supuestas leyes universales objetivas. Y más curioso resulta que insista en criticar el concepto junguiano de arquetipo, justamente, un concepto que dota de un carácter científico a la constatación de la universalidad de determinados procesos psíquicos inconscientes. De tal suerte afirmará: "Según Jung habría significaciones precisas ligadas a ciertos temas mitológicos, que él llama arquetipos" (Lévi-Strauss 1970:188). Queda claro que Lévi-Strauss nunca se tomó la molestia de leer a Jung con detenimiento. Para responder a este tipo de críticas que en realidad no son sino malentendidos, apelo a la respuesta de Jung a tales tergiversaciones de su pensamiento:

Mis ideas acerca de los "remanentes arcaicos", que yo llamo "arquetipos" o "imágenes primordiales", han sido constantemente criticadas por personas que carecen de suficiente conocimiento de psicología de los sueños y de mitología. El término "arquetipo" es con frecuencia entendido mal, como si significara ciertos motivos o imágenes mitológicos determina- 
dos. Pero éstos no son más que representaciones conscientes; sería absurdo suponer que tales representaciones variables fueran hereditarias.

$\mathrm{El}$ arquetipo es una tendencia a formar tales representaciones de un motivo, representaciones que pueden variar muchísimo en detalle sin perder su modelo básico [...] Mis críticos han supuesto erróneamente que me refiero a "representaciones heredadas", y, basados en ello, han desechado la idea del arquetipo como una mera superstición. No han sabido tener en cuenta el hecho de que si los arquetipos fuesen representaciones originadas en nuestra consciencia (o fuesen adquiridos conscientemente), es seguro que los entenderíamos y no nos desconcertaríamos y asombraríamos cuando se presentan en nuestra conciencia. Desde luego, son una tendencia, tan marcada como el impulso de las aves a construir nidos o el de las hormigas a formar colonias organizadas (Jung 1984: 65-66).

En primer término, en la teoría de Jung,la existencia del arquetipo tiene un fundamento biológico. El argumento inicial que se nos presenta es que los seres humanos, al igual que todos los animales, poseen una psique preformada, propia de la especie, que es transmitida por la herencia biológica.

Dada la estructura del cuerpo, sería asombroso si la psique fuera el único fenómeno biológico que no mostrara claras huellas de su historia evolutiva. Es muy probable que las huellas estén en relación muy estrecha con la base instintiva. El instinto y el modus arcaico coinciden con el concepto biológico de patrón de conducta. No existen, por cierto, instintos amorfos; cada instinto tiene un patrón de su situación. Se realiza de acuerdo con una imagen que posee propiedades fijas (Jung 1997: 145).

Para Jung, la idea de John Locke, quien afirmaba que la psique de un niño recién nacido es una tabula rasa, constituye una gran equivocación. El niño nace con un cerebro claramente diferenciado que es el producto de la herencia biológica. Enfrenta los estímulos sensoriales con aptitudes definidas, de lo que resulta una elección particular e individual y un patrón perceptual específico. Así, es posible mostrar que estas aptitudes constituyen instintos heredados y patrones preformados, siendo estos últimos, los a priori y las precondiciones formales 
para la percepción. Su presencia imprime en el niño y en el soñador la estampa antropomórfica.

Se trata de los arquetipos que dirigen la actividad mental (imaginación, intelección, sueño, ensueño, creación) por caminos definidos. Aquí, para evitar confusiones e interpretaciones equívocas, resulta esencial explicitar que el arquetipo constituye el proceso que estructura el pensamiento humano y sólo en ese sentido es el producto de la herencia biológica, sin embargo, el contenido concreto, el significado particular que se le otorga al arquetipo no es heredado, sino producido culturalmente, constituye su aspecto concreto y variable, por ser el resultado del trabajo cultural y personal, desarrollado sobre la base de la estructura arquetípica neurobiológica: es aprendido socialmente. A diferencia de lo que afirman algunos autores que lo malinterpretan, como Lévi-Strauss, Jung nunca afirmó que los contenidos concretos del arquetipo, y por ello culturales, fueran heredados. Para él, claramente, son adquiridos socialmente: lo único heredado es la predisposición psíquica, la estructura y las funciones neurobiológicas de la mente humana.

En el caso de las creaciones de la fantasía infantil o de los delirios de los esquizofrénicos, relata Jung, se producen sorprendentes paralelismos con los sistemas mitológicos de los más diversos pueblos; paralelismos que, en menor grado, también ocurren en los sueños y las fantasías de las personas normales, así como en las de los neuróticos. La existencia universal de los arquetipos asimismo muestra que no son una herencia individual sino genérica, apareciendo tanto en la forma de mitos en el nivel de la historia de los pueblos, como en las funciones psíquicas de la vida individual, contribuyendo a fortalecer la antropogénesis (Jung 1997: 49-68). Al contrastar su experiencia clínica psicoanalítica con sus estudios de antropología religiosa y su experiencia etnográfica en África y Norteamérica, Jung llegó a las siguientes conclusiones:

El concepto de arquetipo [...] se deriva de la observación repetida varias veces de que por ejemplo los mitos y los cuentos de la literatura universal contienen siempre en todas partes ciertos motivos. Estos mismos motivos los hallamos en las fantasías, sueños, delirios e imaginaciones 
de los individuos actuales. Estas imágenes y conexiones típicas se designan como representaciones arquetípicas. Tienen, cuanto más claras son, la propiedad de ir acompañadas por vivos matices afectivos [...] Impresionan, influyen y fascinan. Provienen de un arquetipo imperceptible en sí mismo, de una pre-forma inconsciente que parece pertenecer a la estructura heredada de la psique, y puede, a causa de ello, manifestarse en todas partes como fenómeno espontáneo (1996: 411).

Siendo la psique preformada, lo son también sus funciones particulares, especialmente aquellas que provienen de las predisposiciones inconscientes. La fantasía creadora pertenece a ese campo y gracias a ella se hacen visibles las imágenes primordiales, para las cuales el concepto de arquetipo resulta más pertinente (Jung 1997: 73). El psicólogo ha insistido en disipar el equívoco, surgido de la interpretación errónea de sus ideas sobre el arquetipo; aclara, como hemos señalado, que los arquetipos no son representaciones heredadas ni están determinados en cuanto a su contenido. Así, no se trata de representaciones heredadas sino de posibilidades para que las representaciones concurran en ciertas formas y situaciones. El arquetipo es un elemento formal, vacío en sí, que no es sino una facultas praeformandi, una posibilidad dada a priori de la forma de la representación. Es una estructura formal indeterminable que tiene la posibilidad de aparecer bajo formas determinadas (Jung 1997: 66 y 74).

La tergiversación de las hipótesis de Jung por parte de Lévi-Strauss se hace más evidente cuando éste intenta criticar la distinción junguiana entre inconsciente colectivo e inconsciente personal.

El problema etnológico es, por lo tanto, en último término, un problema de comunicación, y esta constelación es suficiente para separar radicalmente el camino seguido por Mauss al identificar inconsciente y colectivo, del seguido por Jung, a pesar de haberlo intentado definir paralelamente, puesto que no es lo mismo definir el inconsciente como mera categoría del pensamiento colectivo, que clasificarlo en sectores, de acuerdo con el contenido que se le presente, según el carácter individual o colectivo. En ambos casos se concibe el inconsciente como un sistema simbólico, pero para Jung el inconsciente no se reduce a un sistema, ya que está lleno de símbolos y de cosas simbolizadas que le 
crean una especie de sustrato; ahora bien: o este sustrato es innato, lo cual, por otra parte, sin la hipótesis teológica es inconcebible que el contenido de la experiencia le haya precedido, o este sustrato es adquirido, en cuyo caso el problema de la herencia de un inconsciente adquirido no será menos temible que el de los caracteres biológicos adquiridos (LéviStrauss 1979: 28).

En esta otra crítica, la confusión de Lévi-Strauss es total, pues continúa entendiendo de manera equívoca el planteamiento de Jung, para el cual, tal como hemos aclarado, lo que es producto de la herencia biológica es la función psíquica, el funcionamiento neurobiológico, común a todos los seres humanos y lo que es producido culturalmente y, por ello, diferencial, en cada caso, es el contenido concreto que se le atribuye al arquetipo. Para él, es muy claro que el contenido no puede ser producto de la herencia, puesto que sólo puede ser adquirido socialmente en un contexto cultural específico. De ahí que su distinción entre inconsciente colectivo e inconsciente personal sirva para diferenciar la función psíquica universal que es propia del inconsciente colectivo, es decir, de la herencia biológica común, del contenido particular, que es aprendido por las personas dentro de los procesos sociales, de manera personal, y es propio del inconsciente personal.

Un estrato en cierta medida superficial de lo inconsciente es, sin duda, personal. Lo llamamos inconsciente personal. Pero este estrato descansa sobre otro más profundo que no se origina en la experiencia y la adquisición personal, sino que es innato, lo he llamado inconsciente colectivo. Elegí la expresión "colectivo" porque este inconsciente no es de naturaleza individual sino universal, es decir, que en contraste con la psique individual tiene estructuras y modos de comportamiento que son, cum grano salis, los mismos en todas partes y en todos los individuos. En otras palabras, es idéntico a sí mismo en todos los hombres y constituye así un fundamento anímico de naturaleza suprapersonal existente en todo hombre (Jung 1997: 10).

Como hemos podido ver, el contraste crítico entre la teoría junguiana del arquetipo y la teoría de Lévi-Strauss acerca de la actividad inconsciente del espíritu humano deja mal librada a ésta última, mientras que 
la primera está bien fundada, la segunda carece de argumentos sólidos que la sustenten. Al entender el uso del lenguaje y la vida cultural como productos de la actividad de un espíritu inconsciente, Lévi-Strauss niega el carácter activo de la relación humana con la cultura y ve a la humanidad desde la perspectiva del sistema informático y del hormiguero: en ambos casos se trata de procesos carentes de acción humana consciente, de procesos ciegamente repetitivos, automáticos, carentes de toda reflexión. En cambio, en la vertiente junguiana podemos observar la manera compleja en la cual el ser humano hace uso, de manera polimorfa, diferencial y creativa, de los dones que ha recibido a partir de la herencia biológica. Así, quien aparentemente parecía sostener una teoría científicamente fundamentada, Lévi-Strauss, resultó defender una perspectiva metafísica y, al revés, quien parecía defender una teoría metafísica, Jung, resultó poseer una teoría bien fundada en términos científicos.

\section{Bibliografía}

AmAdor Bech, Julio (2011). "Los modelos de comunicación y los límites del estructuralismo", Derecho a comunicar, Revista científica de la Asociación Mexicana del Derecho a la Información, núm. 2, mayo-agosto: 13-35.

BARTHES, Roland [1985] (1993). La aventura semiológica. Barcelona, Paidós.

CARdona, Giorgio Raimondo [1990] (1994). Los lenguajes del saber. Barcelona, Editorial Gedisa.

CомтE, Augusto [1842] (2004). Curso de filosofía positiva. Buenos Aires, Ediciones Libertador.

Descartes, René (1971). Reglas para la dirección del espíritu, México, Editorial Porrúa;

Descartes, René (1993). Discurso del método. Barcelona, Altaya.

Dilthey, Wilhelm [1883] (1978). Introducción a las ciencias del espíritu, Obras Completas, Vol. México, Fondo de Cultura Económica.

Duch, Lluís, et al. (2008). Lluís Duch, antropología simbólica y corporeidad cotidiana, México, Universidad Nacional Autónoma de México/CRIM.

Durand, Gilbert [1964] (1971). La imaginación simbólica. Buenos Aires, Amorrortu Editores.

- (1993). De la mitocrítica al mitoanálisis, Figuras míticas y aspectos de la obra. Barcelona, Anthropos/Universidad Autónoma de México. 
Duvignaud, Jean [1973] (1977). El lenguaje perdido. Ensayo sobre la diferencia antropológica. México, Fondo de Cultura Económica;

- (1981). "Institución y juego", entrevista por Julio Amador Bech, Revista Palos de la crítica, núm. 2-3, octubre 1980-marzo 1981.

Eco, Umberto [1968] (1994). La estructura ausente. Introducción a la semiótica. Barcelona, Editorial Lumen.

Ferraris, Maurizio (2002). Historia de la hermenéutica. México, Siglo XXI Editores.

GAdAmer, Hans-Georg (1999). Verdad y método. Salamanca, Ediciones Sígueme.

GeErtz, Clifford (1997). La interpretación de las culturas. Barcelona, Gedisa.

- [1983] (2000). Local Knowledege. Lexinton, Basic Books.

- (2001). Available Light. Anthropological Reflections on Philosophical Topics. Princeton, Princeton University Press.

Gurvitch, Georges (1979). "Prólogo a la primera edición” (1950), en Marcel Mauss, Sociología y antropología. Madrid, Editorial Tecnos.

Hegel, Georg Wilhelm Friedrich [1807] (1973). Fenomenología del espíritu. México, Fondo de Cultura Económica.

HeIDEgGer, Martin [1923] (2000). Ontología. Hermenéutica de la facticidad. Madrid, Alianza Editorial.

- [ [927] (2008). El ser y el tiempo. México, Fondo de Cultura Económica;

- [1962] (2009). La pregunta por la cosa. Sevilla/Madrid/Lisboa/México/ Buenos Aires/Bogotá, Palamedes Editorial-Publidisa.

Hymes, Dell (1974). Foundations in Sociolinguistics, An Ethnographic Approach, Philadelphia, University of Pennsylvania Press.

Jung, Carl Gustav (1971). Tipos Psicológicos. Buenos Aires, EDHASA.

- (1984). El hombre y sus símbolos. Barcelona, Caralt.

- (1996). Recuerdos, sueños, pensamientos. Barcelona, Seix Barral.

- [1934/I954] (1997). Arquetipos e inconsciente colectivo. Barcelona, Paidós.

Kerbrat-orecchioni, Catherine (1997). La enunciación. De la subjetividad en el lenguaje. Edicial, Buenos Aires.

LEROY, Maurice [1964] (1992). Las grandes corrientes de la lingüística. México, Fondo de Cultura Económica.

LÉvi-STRAuss, Claude (1970). Antropología estructural. La Habana, Instituto del Libro/Editorial de Ciencias Sociales.

- (1979). "Introducción a la obra de Marcel Mauss", en Marcel Mauss, Sociología y antropología. Madrid, Editorial Tecnos: 13-42. 
LÉVI-STRAuss, Claude [1968] (1981). El origen de las maneras de mesa. Mitológicas III. México, Siglo XXI Editores.

- [1949] (1985). Las estructuras elementales del parentesco. México, Origen/Planeta.

- (1994). El pensamiento salvaje. México, Fondo de Cultura Económica;

- [1964] (1996). Mitológicas I. Lo crudo y lo cocido. México, Fondo de Cultura Económica.

Mauss, Marcel [1923-1924] (1979). Sociología y antropología. Madrid, Editorial Tecnos.

- (1971). Institución y culto, Obras II. Barcelona, Barral Editores.

RiCOEUR, Paul [1980] (1999). Historia y narratividad. Barcelona, Paidós/Instituto de Ciencias de la Educación de la Universidad Autónoma de Barcelona.

- (2003). El conflicto de las interpretaciones. Ensayos de hermenéutica. Buenos Aires, Fondo de Cultura Económica.

- (2006). Teoría de la interpretación. Discurso y excedente de sentido. México, Siglo XXI Editores/Universidad Iberoamericana.

- (2007). Tiempo y narración I, Configuración del tiempo en el relato histórico. México, Siglo XXI Editores.

Saussure, Ferdinand de, (1979). Curso de lingüística general. Buenos Aires, Editorial Losada.

Shannon C. E. y Warren WeAver (1949). The Mathematical Theory of Communication. Chicago, University of Illinois.

Wiener, Norbert (1965). Cybernetics or Control and Communications in the Animal and the Machine. Massachusetts, Massachusetts Institute of Technology.

Winkin, Yves (1984). "Presentación general”, en Gregory Bateson, La nueva comunicación. Barcelona, Editorial Kairós. 